\title{
Oral rehabilitation in a patient with special needs
}

\author{
Tratamento reabilitador em paciente especiaL
}

\author{
Juliana dos Reis DERCELI' \\ Lígia Antunes Pereira PINELLI² \\ Elisa Maria Aparecida $\mathrm{GIRO}^{3}$ \\ Juliana CABRINI ${ }^{1}$ \\ Sabrina Maria CASTANHARO' \\ Laiza Maria Grassi FAIS ${ }^{1}$
}

\begin{abstract}
Cerebral palsy is a disorder caused by central nervous system injuries that can occur during the prenatal, perinatal, or postnatal periods. It is characterized by multiple abnormalities, including impairment of speech, body and motor coordination, balance, intelligence, mastication, and swallowing. Due to abnormal movements of the facial muscles, compounded by impairment of the self-cleansing mechanism of the oral cavity, patients with this condition can develop oral diseases such as caries, periodontal disease, and tooth loss. The aim of this paper is to report a case of a patient with cerebral palsy who presented with absence of the maxillary central incisors, removable prosthesis wear, and oral candidiasis. Impressions of the upper and lower arches and periapical radiographs were obtained. The lateral incisors were found to exhibit root resorption, which contraindicated their use as abutment teeth for fixed prosthodontics. In view of the patient's socioeconomic status and cerebral palsyrelated limitations, a resin-bonded fixed partial denture was fabricated and nystatin solution was used for treatment of oral candidiasis. The patient had an esthetically and functionally adequate outcome.
\end{abstract}

Indexing terms: Cerebral palsy. Oral candidiasis. Oral rehabilitation.

\section{RESUMO}

A paralisia cerebral é uma anormalidade causada por lesões no sistema nervoso central que podem ocorrer durante o período pré, peri ou pósnatal. É caracterizada por alterações múltiplas como o comprometimento da fala, da coordenação motora e corporal, do equilíbrio, do intelecto e da mastigação e deglutição. Devido aos movimentos anormais da musculatura facial, juntamente com o comprometimento da função de autolimpeza, o paciente pode apresentar quadros de patologia bucal como a cárie, a doença periodontal e a perda dental. O objetivo deste trabalho foi relatar o caso clínico de um paciente portador de paralisia cerebral com ausência dos incisivos centrais superiores, portador de prótese removível e com um quadro de candidose bucal. Foi realizada a moldagem dos arcos superior e inferior e as radiografias periapicais. Pôde-se observar que os incisivos laterais apresentavam reabsorção radicular, o que contra indicava a sua utilização como pilares para prótese fixa. Devido às condições sócio-econômicas e limitações relacionadas a paralisia cerebral, foi confeccionada uma prótese adesiva e, para a candidose bucal foi instituído o tratamento com solução de Nistatina. O resultado do tratamento foi estética e funcionalmente adequado para o paciente.

Termos de indexação: Paralisia cerebral. Candidíase bucal. Reabilitação bucal.

\section{INTRODUCTION}

Cerebral palsy (CP) is characterized by abnormalities in the controlled or postural movements of the body secondary to central nervous system injury, damage, or dysfunction, and is not known to be the result of a progressive or degenerative brain disease ${ }^{1-2}$. The insult may occur during the prenatal, perinatal, or postnatal period ${ }^{2-3}$. The clinical picture usually involves delayed motor development, persistence of primitive reflexes, presence of abnormal reflexes, and deficient development of protective reflexes ${ }^{1}$.
Individuals with CP are often afflicted with multiple disabilities, including impaired body control, upper, and/or lower limb coordination; posture and balance; mastication and swallowing; speech; sensory perception; intellectual capacity; and emotional control and behavior ${ }^{4}$.

Due to abnormal movement of the facial muscles, there may be prolonged food retention in the oral cavity, with impairment of self-cleansing mechanisms and incontinence of saliva; as a result of these factors, oral hygiene is considered unsatisfactory ${ }^{5}$.

\footnotetext{
${ }^{1}$ Universidade Estadual Paulista Júlio de Mesquita Filho, Faculdade de Odontologia. Rua Humaitá, 1680, Centro, 14801-903, Araraquara, SP, Brasil. Correspondência para / Correspondence to: JR DERCELI. E-mail: <julianaderceli@gmail.com>.

${ }^{2}$ Universidade Estadual Paulista Júlio de Mesquita Filho, Faculdade de Odontologia, Departamento de Materiais Dentários e Prótese. Araraquara, SP, Brasil.

${ }^{3}$ Universidade Estadual Paulista Júlio de Mesquita Filho, Faculdade de Odontologia, Departamento de Clínica Infantil. Araraquara, SP, Brasil.
} 
There are no specific oral conditions associated with CP. However, those conditions that affect the general population may be exacerbated in patients with $\mathrm{CP}$, due to the motor impairments inherent to the disorder. Carious lesions, gingival and periodontal abnormalities, malocclusion, and bruxism are the most prevalent alterations ${ }^{6}$ and may be considered determining factors of early tooth loss and, consequently, a need for prosthetic rehabilitation in these patients. Souza \& Tamaki ${ }^{7}$ reported several measures that should be taken when planning and fabricating prosthodontics so as to prevent injury to the oral mucosa. Budtz-Jorgensen ${ }^{8}$ noted that, in addition to the trauma caused by the prosthesis itself, poor denture hygiene is a predisposing factor for the development of oral candidiasis, a condition in which development of the microorganism depends on the individual's overall health status. According to some authors, $5,9-15$, the motor impairments of patients with CP reduces the possibility of maintaining adequate oral hygiene, which may lead to the development of oral diseases. Therefore, in most cases, caregivers must take charge of the patient's oral hygiene.

It is common for oral hygiene to be performed "at bath time", only once or twice a day; this low brushing frequency may be explained by caregiver difficulties in dealing with the patient ${ }^{16}$. Faulks \& Hennequim ${ }^{17}$ noted that parents are somewhat neglectful of these patients' oral hygiene. Therefore, patients with CP should be encouraged to perform their own oral hygiene practices whenever possible.

The oral health of patients with special needs remains very precarious, not least in Brazil. Several reasons explain this phenomenon: few centers specialize in caring for patients with special needs; very few dentists are willing to care for such patients in private practice; dental care is quite expensive; and, especially, the lack of education, motivation, and interest by family members to care for the oral health of these patients ${ }^{18}$.

Within this context, the aim of this paper is to report the case of a patient with cerebral palsy who presented with absence of the maxillary central incisors, removable prosthesis wear, and oral candidiasis.

\section{CASE REPORT}

\section{Clinical history}

O.F.M.J., a 21-year-old male with cerebral palsy, received multidisciplinary oral rehabilitation care within the purview of the "Dental Service for Special Needs Patients"
Extension Project of the Departments of Pediatric Dentistry and Fixed Prosthodontics at Faculdade de Odontologia de Araraquara-UNESP. The patient was a mouth breather and had Angle class II malocclusion, with a marked overjet. He had lost teeth \#11 and \#21 as a result of trauma. The patient wore a temporary removable partial denture (Figure 1), which was esthetically compromised at the time of presentation, and had severe oral candidiasis of the palate and alveolar cleft, which had persisted despite prior treatment with nystatin. The patient was chaperoned by his biological father and was quite receptive to dental care. Communication with the patient was easy, despite his impaired speech and motor coordination.

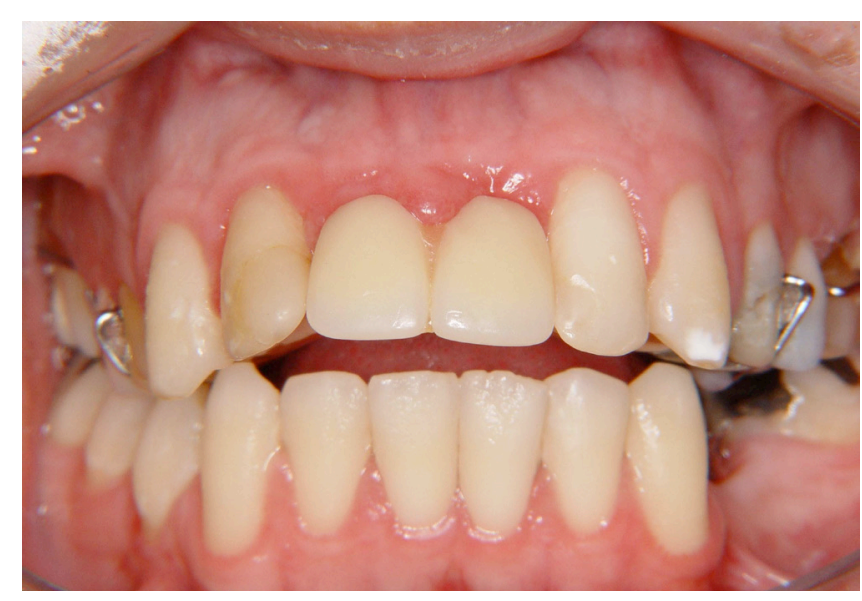

Figure 1. Temporary removable partial denture with compromised esthetics.

\section{Treatment plan}

In an attempt to clear the patient's candidiasis and improve the esthetics of his teeth, we elected to use fixed prosthodontics. However, on radiographic examination, the patient's maxillary lateral incisors were found to lack adequate bone support, which precluded their use as abutment teeth for a fixed prosthesis (Figure 2). One alternative would have been to extract the lateral incisors and use the canines as abutments for the fixed prosthesis. In view of the less conservative nature and higher cost of this option, in a consensus decision with the patient's father, we chose a more conservative alternative instead; namely, to preserve the lateral incisors and place a resinbonded fixed partial denture. 


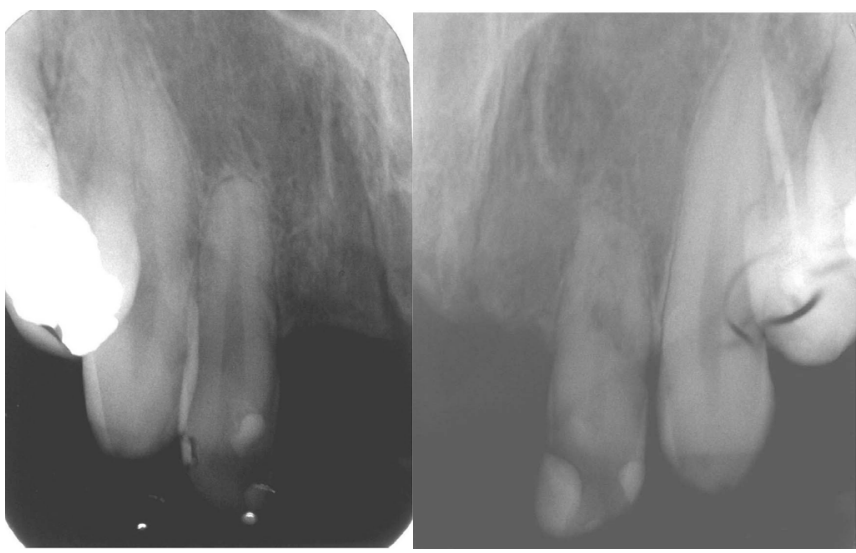

Figure 2. Radiographs showing lack of adequate bone support for teeth \#12 and \#22.

\section{Treatment}

A temporary, resin-bonded, fixed partial denture was fabricated and placed to restore esthetics. For treatment of oral candidiasis, the patient was prescribed topical application of nystatin solution, three times a day for 15 days.

Impressions of the upper and lower arches were obtained with irreversible hydrocolloid material (Jeltrate Dentsply, Catanduva, São Paulo, Brazil) and used to obtain stone casts (Durone Dentsply, Catanduva, São Paulo, Brazil) (Figure 4). These models, in turn, were used for case study and diagnostic wax-up of teeth \#11 and \#21.

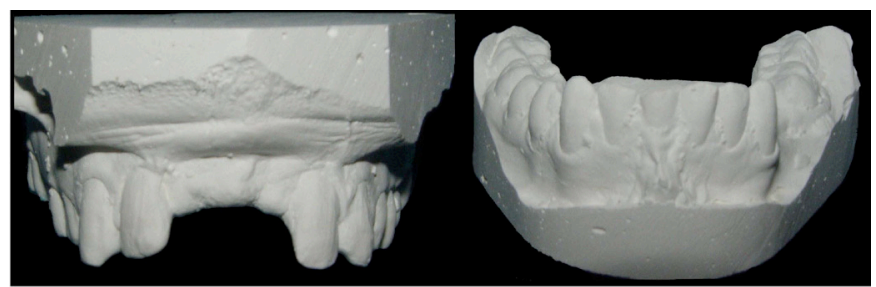

Figure 3. Upper and lower study models.

Pontics were made from an impression of the diagnostic wax-up of the central incisors, using light-cured composite resin (Charisma, Heraeus Kulzer, São Paulo, Brazil).

Under rubber dam isolation, retention grooves were placed on the palatal surfaces of the adjacent teeth $(12,22,13$, and 23), using a \#3099 diamond bur (KG Sorensen, São Paulo, Brazil) (Figure 5).

After acid etching and application of primer and adhesive to the enamel of the teeth adjacent to the edentulous space, the pontics were bonded to these teeth

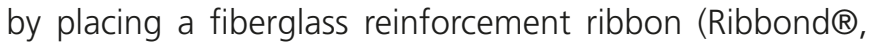
Seattle, WA, USA) and luting with light-cure composite resin (Charisma, Heraeus Kulzer, São Paulo, Brazil) to the grooves placed on the palatal surfaces of the lateral incisors and canines (Figure 4). After light cure of the composite resin, the denture was finished and polished to a satisfactory standard (Figures 5 and 6).
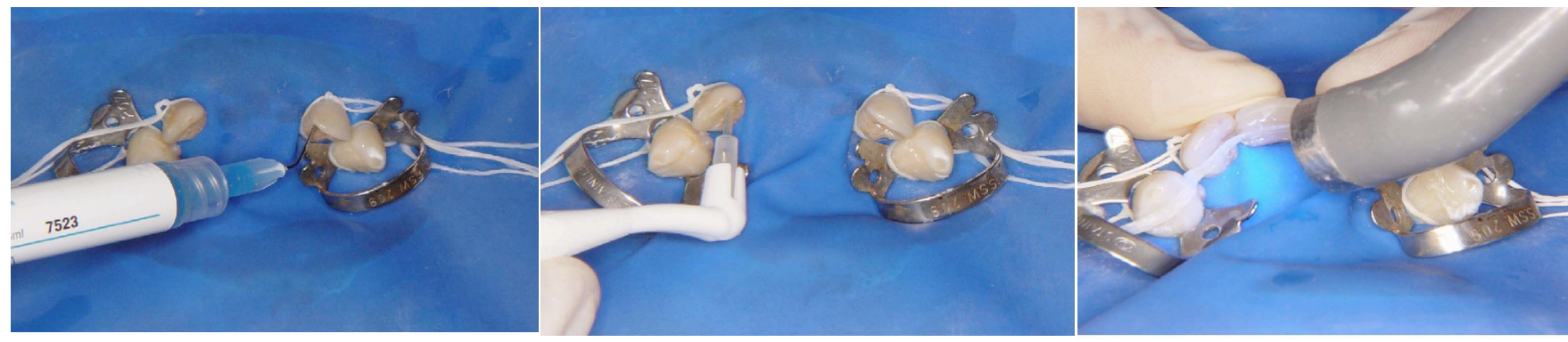

Figure 4. Acid etching of the palatal surfaces of the teeth, bonding agent application, fiberglass ribbon placement, and light cure of composite resin.

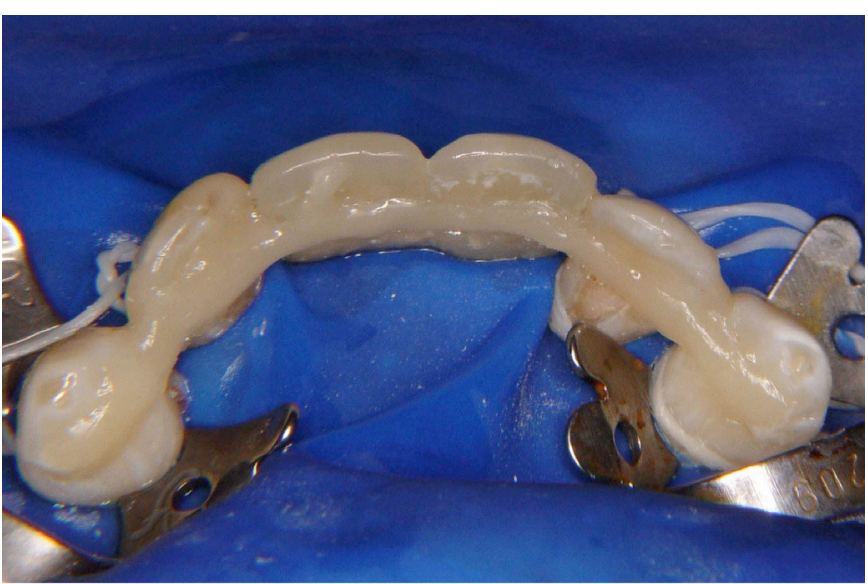

Figure 5. Palatal view of the resin-bonded fixed partial denture.

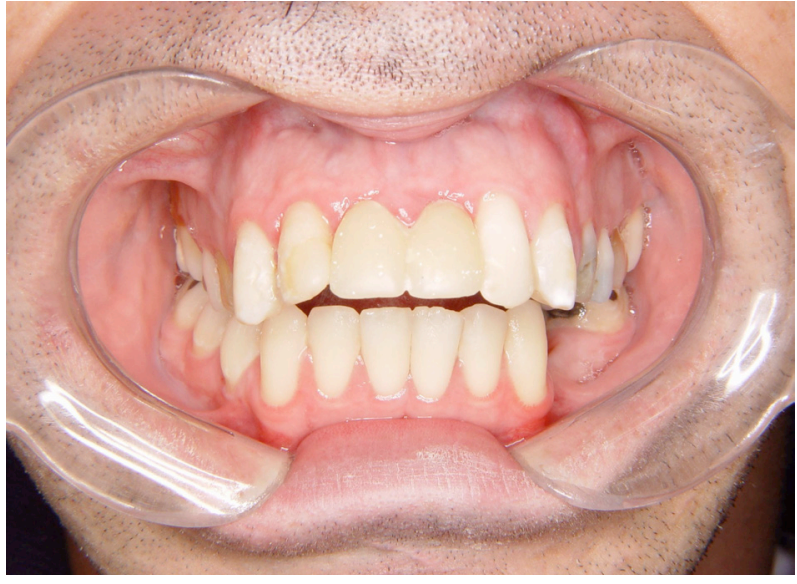

Figure 6. Esthetic view of the resin-bonded fixed partial denture. 


\section{Follow-up}

One week after prosthesis fit, the patient returned for a follow-up assessment. The prosthesis was stable and both the patient and his family reported excellent satisfaction with the treatment provided. There was also improvement of his candidiasis. At 2-month follow-up, candidiasis continued to improve, with decreased erythema of the palate and anterior cleft, and the prosthesis was functionally and esthetically appropriate.

\section{DISCUSSION}

As a result of scientific advancements that have improved the survival of individuals with special needs, there has been a substantial increase in the number of such patients who seek dental care ${ }^{19-20}$. Therefore, dental practitioners must be aware of how to proceed when faced with a patient with special needs. It should be noted that patients with special needs exhibit severe oral compromise, which often leads to tooth loss and infections, as stated by Nunn \& Murray ${ }^{21}$ and Grunsven \& Cardoso 22 . Socioeconomic and cultural factors, as well as a lack of caregiver awareness about the oral hygiene of these patients, act as aggravating factors for the development of caries, periodontal disease, and, consequently, tooth loss. As these patients often exhibit severe motor impairment and a limited understanding of reality, they are incapable of performing oral self-care, and are thus dependent on their family members or caregivers for oral hygiene ${ }^{3,18}$. Thus, dentists, caregivers, and other providers must pay particularly close attention to the oral health of patients with special needs ${ }^{23-24}$.

Oral rehabilitation can improve the quality of life of patients with special needs, by providing added masticatory efficiency, improving social interaction, and boosting self-esteem. Regarding prosthetic rehabilitation, care in the fabrication of the prosthesis is essential, so

\section{REFERENCES}

1. Russman. Cerebral palsy: a rational approach to a treatment protocol, and the role of botulinum toxin in treatment. Muscle Nerve Suppl. 1997;6:S181-93.

2. Ferraretto I, Souza MC. Paralisia cerebral: aspectos práticos. São Paulo: Memnon; 1998.

3. Silva MI. Paralisia cerebral: mito e realidade. J AME. 2007;(65). as to provide appropriate microorganism control and enable biological integration of the prosthesis without jeopardizing the longevity of the abutment teeth. Oral candidiasis does not carry the potential for serious morbidity, but an inflamed oral mucosa may pose a hindrance to prosthesis wear ${ }^{25}$. Costa et al. ${ }^{26}$ noted that prosthodontics can contribute to the development of certain oral disorders, depending on the procedures performed by the dentist, the lab, and patients themselves. Infections caused by Candida albicans are the most common oral disorders in denture wearers. The severity of infection depends on systemic health status, oral hygiene, and denture hygiene practices ${ }^{8}$.

In the patient described herein, the combination of removable denture wear and mouth-breathing was considered an etiological factor for the development of candidiasis, in the palate and alveolar cleft region, which was refractory to antifungal therapy. Replacement of the removable prosthesis with a resin-bonded fixed partial denture not only improved esthetics, streamlined the oral hygiene process, and increased patient comfort, but also enabled effective treatment of oral candidiasis, thus improving the patient's quality of life.

The role of dentists in the care and education of special-needs patients and their families in matters of oral health is of paramount importance. All dental practitioners must be prepared to treat and advise such patients and their family members ${ }^{25}$.

\section{CONCLUSION}

Although the chosen treatment option of a fixed prosthesis is temporary, it met the expectations of the patient and his family, enabling adequate oral hygiene and management of candidiasis, thus restoring oral health, function, and esthetics, and, consequently, providing the patient with greater independence and improved quality of life
4. Mugayar LRF. Pacientes portadores de necessidades especiais: manual de odontologia e saúde oral. São Paulo: Pancast; 2000.

5. Isshiki $Y$, Kitafusa $Y$, Iguchi $H$. Caries prevalence in crippled children especially on environmental variation. Bull Tokyo Dent Coll. 1970;11(3):177-92.

6. Figueiredo JR. Odontologia em paralisia cerebral. In: Souza AMC, Ferrareto I. Paralisia cerebral: aspectos práticos. São Paulo: Menon; 1998. p.148-68. 
7. Souza $C P$, Tamaki R. Implicações do uso da prótese total na geriatria. Robrac. 1996;6(19):29-31.

8. Budtz-Jorgensen E. Oral mucosal lesions associated with the wearing of artificial dentures. J Oral Pathol Med. 1981;10(2):65-80.

9. Wessels KE. Oral conditions in cerebral palsy. Dent Clin North Am. 1960;4(14):455-68.

10. Album MM, Cohen MM. The handcapped child: dental treatment for the handicapped child. In: Cohen MM. Pediatric dentistry. $2^{\text {nd }}$ ed. St Louis: Mosby; 1961. p. 286-305.

11. Fagen GM. Dentistry for the cerebral palsied child. Dent Stud. 1968;46(8):606.

12. Brown JP. A review of controlled surveys of dental disease in handicapped persons. ASDC J Dent Child. 1976;43(5):313-20.

13. Kavanagh J. The dental treatment of the cerebral palsied patient. J Dent Que. 1982:19:47-52

14. Tomita NE, Fagote BF. Programa educativo em saúde bucal para pacientes especiais. Odontol Soc. 1999;1(2):45-50.

15. Guaré RO, Ciamponi AL. Dental caries prevalence in the primary dentition of cerebral-palsied children. J Clin Pediatr Dent. 2003;27(3):287-92.

16. Storhaug K, Holst D. Caries experience of disabled school-age children. Community Dent Oral Epidemiol. 1987;15(3):144-9. doi: 10.1111/j.1600-0528.1987.tb00503.x

17. Faulks D, Hennequin M. Evaluation of a long-term oral health program by carers of children and adults with intellectual disabilities. Spec Care Dentist. 2000;20(5):199-208.

18. Aguiar SM, Vila P, Santos-Pinto R. Prevalência de cárie dental em paciente com retardo mental por lesão anóxia cerebral. Ambito Odontol. 1991;(6):124-7.
19. Waldman HB, Perlman SP. Children with disabilities are aging out of dental care. ASDC J Dent Child. 1997;64(6):385-90.

20. Mitsea AG, Karidis AG, Bakoyianni CD, Spyropoulos ND. Oral health status in Greek children and teenagers, with disabilities. J Clin Pediatr Dent. 2001;26(1):111-8. doi: 10.17796/ jcpd.26.1.705 $15693372 \mathrm{k} 1 \mathrm{~g} 7$

21. Nunn JM, Murray JJ. The dental health of handicapped children in Newcastle and Northumberland. Br Dent J. 1987;162(1):9-14.

22. Grunsven MFV, Cardoso EBT. Atendimento odontológico em crianças especiais. Rev Assoc Paul Cir Dent. 1995;49(5):364-70.

23. Flório FM, Basting RT, Salvatto MV, Migliato KL. Saúde bucal em indivíduos portadores de múltiplas deficiências. RGO - Rev Gaúch Odontol. 2007;55(3):251-6.

24. Scalércio M, Valente T, Israel MS, Ramos ME. Estomatite protética versus candidíase: diagnóstico e tratamento. RGO - Rev Gaúch Odontol. 2007;55(3):395-8

25. Silva EMM, Silva-Filho CE, Nepomuceno VC. Uma grande descoberta: o prazer que uma higienização bucal correta e bem orientada pode proporcionar. Rev Odontol Araçatuba. 2003;24(2):39-42.

26. Costa MM, Oliveira JEC, Prado CJ. As próteses removíveis e as iatrogenias evitáveis. ROBRAC. 1997;6(21):11-3.

Received on: 16/9/2014

Final version resubmitted on: 21/10/2014

Approved on: 5/12/2014 
